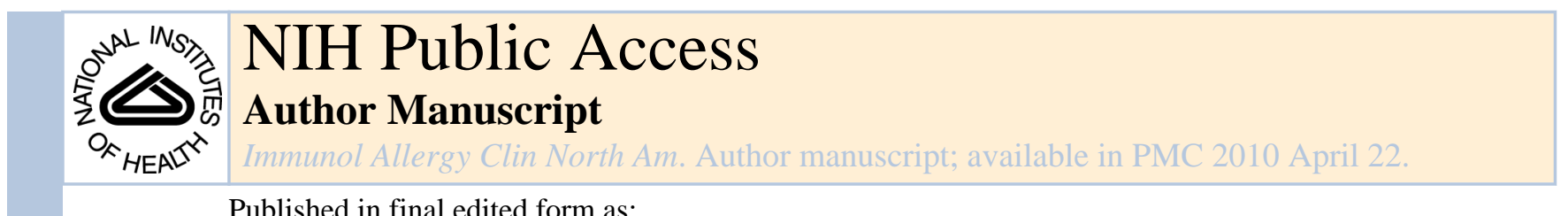

Immunol Allergy Clin North Am. 2007 November ; 27(4): 597-vi. doi:10.1016/j.iac.2007.09.006.

\title{
Exhaled breath condensate $\mathrm{pH}$ assays
}

\author{
John Hunt, MD [Associate Professor of Pediatrics] \\ Pulmonology, Allergy \& Immunology Box 800386 University of Virginia Charlottesville, VA 22908 \\ Jfh2m@virginia.edu 434 243-9377
}

\section{Introduction}

Airway $\mathrm{pH}$ is central to the physiologic function and cellular biology of the airway. The causes of airway acidification include: 1) hypopharyngeal gastric acid reflux with or without aspiration through the vocal cords; 2) inhalation of acid fog or gas (such as chlorine); 3 ) intrinsic airway acidification caused by altered airway $\mathrm{pH}$ homeostasis in infectious and inflammatory disease processes(1). The recognition that relevant airway $\mathrm{pH}$ deviations occur in lung diseases is opening doors to new simple and inexpensive therapies(2). In part, this recognition has resulted from the ability to use exhaled breath condensate (EBC) as a window on airway acid-base balance, about which data are otherwise difficult or ethically impossible to obtain.

EBC consists primarily of water with trapped aerosolized droplets from the airway lining fluid, as well as water-soluble volatile compounds. The $\mathrm{pH}$ of EBC is determined primarily by the water-soluble volatile gases(3-5) and reflects (but does not precisely quantitate) airway lining fluid $\mathrm{pH}$. A low $\mathrm{pH}$ value in $\mathrm{EBC}$ results from the enhanced volatilization of acids that occurs from an acidic source: in other words, an acidic airway lining fluid. Nonvolatile basic anions become protonated within an acidic airway lining fluid and thereby turn into volatile (exhalable) acids. Formic and acetic acid(6), as well as numerous other acids, join the exhaled airstream when the airway is acidic, are captured by the water condensing in the exhaled breath, and lower the $\mathrm{pH}$ of the EBC. In contrast, when the airway lining fluid is alkaline, the ionized conjugate bases of these acids are the dominant species. The ionized conjugate bases are not volatile, and therefore not appreciably exhaled(5). The association of low airway $\mathrm{pH}$ with low $\mathrm{EBC} \mathrm{pH}$ has been proven empirically with studies of experimental airway acidification in cows(7). These straightforward concepts have allowed a simple assay $(\mathrm{pH})$, performed on easily collected sample $(\mathrm{EBC})(8)$, to provide large amounts of data regarding airway acidity from patients even in the presence of marked acute airway disease $(9,10)$.

\section{Addressing the artifact of carbon dioxide}

Most investigators, but not all, address in some manner the important issue of carbon dioxide affecting the $\mathrm{EBC} \mathrm{pH} . \mathrm{CO}_{2}$ is a volatile gas that is a precursor to carbonic acid. $\mathrm{CO}_{2}$ is not appreciably more volatile from acidic airway lining fluid than from alkaline airway lining fluid. Although $\mathrm{CO}_{2}$ contributes to the acidity of airway lining fluid, the presence of

\footnotetext{
Publisher's Disclaimer: This is a PDF file of an unedited manuscript that has been accepted for publication. As a service to our customers we are providing this early version of the manuscript. The manuscript will undergo copyediting, typesetting, and review of the resulting proof before it is published in its final citable form. Please note that during the production process errors may be discovered which could affect the content, and all legal disclaimers that apply to the journal pertain.

Conflict of Interest: JH is a cofounder of Respiratory Research, Inc., which manufactures exhaled breath condensate collection equipment. JH and the University of Virginia have intellectual property interest in airway pH diagnosis and therapy.
} 
$\mathrm{CO}_{2}$ in $\mathrm{EBC}$ does not communicate that the airway lining fluid is acidic, because the $\mathrm{CO}_{2}$ will be there affecting the $\mathrm{pH}$ of the $\mathrm{EBC}$ irregardless of the airway $\mathrm{pH} . \mathrm{CO}_{2}$ leads to substantial EBC acidification if not accounted for in some fashion and provides noise in the system that limits the ability to identify the smaller effects of the volatile acids, and shrinks the overall effect size of $\mathrm{pH}$ measurements in disease by lowering the $\mathrm{EBC} \mathrm{pH}$ normal range. Gas standardization either with a " $\mathrm{CO}_{2}$-free gas"(8) or with a gas that contains a known quantity of $\mathrm{CO}_{2}$ (11) seems wise, and has been commonly adopted.

Gas standardization prior to EBC $\mathrm{pH}$ measurement allows for samples to be assayed at any time after collection, and clearly improves assay repeatability and overall reproducibility in patient collections $(3,11)$. Not all $\mathrm{CO}_{2}$ is removed by gas standardization by means of exposing (bubbling) the sample with a " $\mathrm{CO}_{2}$-free" gas, in part because it is unlikely that the standardizing gas is truly $\mathrm{CO}_{2}$-free. Overall, however, the levels of $\mathrm{CO}_{2}$ in $\mathrm{EBC}$ are brought to similar relatively low levels for all samples during gas standardization, but some minor effect of residual $\mathrm{CO}_{2}$ remains.

The recent work of Horvath's group in Hungary(11) has raised the possibility that using a known concentration of $\mathrm{CO}_{2}$ for gas standardizing may improve reproducibility of the assay further. There is some loss of effect size between disease and health by so doing, but standardizing on a known concentration of $\mathrm{CO}_{2}$ may allow for more interlaboratory cooperation. Using " $\mathrm{CO}_{2}$-free" gas does allow for variable amounts of contaminating $\mathrm{CO}_{2}$, which — in addition to EBC collection equipment differences--may in part explain why there is some variability of normal in different laboratories.

It should not be a surprise that the volatile acids trapped in EBC are not as affected by gas standardization procedures as the $\mathrm{CO}_{2}$ is. This is simply because $\mathrm{CO}_{2}$ is a highly volatile gas that is a precursor of an acid, as opposed to an acid itself, whereas the volatile acids that acidify $\mathrm{EBC}$ are trapped by ionization. $\mathrm{CO}_{2}$ is relatively easy to remove from solution, which likewise removes the carbonic acid that was formed when $\mathrm{EBC}$ initially absorbed the $\mathrm{CO}_{2}$. Thus, the unhelpful effect of exhaled $\mathrm{CO}_{2}$ on $\mathrm{EBC} \mathrm{pH}$ is minimized by having the EBC "breathe it back off" during gas standardization.

\section{EBC $\mathrm{pH}$ assay validation and technical issues}

The gas standardized EBC $\mathrm{pH}$ measurements are substantially reproducible and immune to most potential confounding influences. In comparison to other EBC assays, $\mathrm{pH}$ is solidly in the range of available assays. Although EBC is a dilute fluid with low ionic strength, there are available $\mathrm{pH}$ probes that are designed to function even in distilled water. Thus $\mathrm{EBC} \mathrm{pH}$ measurement has benefited from the decades of advances in measurement of this standard chemical property. There are readily available technological capabilities to assess concentrations of hydrogen ions as low as 10 femtomolar (which is equivalent to an alkaline $\mathrm{pH}$ of 14) and as high as 1 molar (an acid $\mathrm{pH}$ of 0 ). Measurement of $\mathrm{pH}$ is routinely performed, even in highly purified water such as that used in steam turbines. Measurement of $\mathrm{pH}$ of fluids is a well-understood process with no technical hurdles to overcome.

Our center has specifically examined, and found no effect on the final deaerated EBC pH value of any of the following factors: age (5-75 years), gender or race, time of day collected, volume of EBC collected and duration of EBC collection, degree of hyperventilation or hypoventilation of the subject, temperature or duration of sample storage, choice of $\mathrm{CO}_{2}$-free gas used for deaeration (oxygen vs. argon), acute use of albuterol/salbutamol by the patient, oral ammonia, or methacholine-induced airway obstruction $(3,4,8,12)$. Note that early data from our laboratory suggest that the very old (> 80 years) reveal more EBC acidification than the rest of the population (unpublished observations). 
There do seem to be effects on $\mathrm{EBC} \mathrm{pH}$ arising from condenser temperature during collection. In healthy subjects (without breath acidification), we found no difference in EBC $\mathrm{pH}$ with temperature of collection down to $-56^{\circ} \mathrm{C}$ to room temperature. However, in subjects with acidic breath, collecting at condenser temperatures low enough to cause sample freezing is found to lead to less capture of exhaled acids (which cannot go into solution into ice, after all). Thus we always perform EBC collection at temperatures that do not allow sample freezing during collection.

An additional effect on $\mathrm{pH}$ arises during sample storage while frozen. We have noted that after freezing a stored sample with low $\mathrm{pH}$, if the sample container is opened before thawing the measured $\mathrm{pH}$ of the sample is higher than the initial measurement. These observations are consistent with sublimation from the solid EBC of relevant volatile acids-a conclusion supported by the ability to prevent this artifact from occurring by allowing the sample to thaw and shaking the container before opening it. Indeed, we strongly recommend this approach.

A final technical comment regarding EBC $\mathrm{pH}$ measurement seems warranted. Not all $\mathrm{pH}$ probes are appropriate for measurement in the low ionic strength matrix of EBC. Certain technologies simply will not function. We have found that Ross-type $\mathrm{pH}$ probes are uniformly effective and standard glass probes with a substantial leak of internal fluid are generally effective. Before we select a probe for our studies, we confirm that it calibrated in low ionic strength buffers identically to normal $\mathrm{pH}$ buffers, and that addition of ionic strength adjusters/enhancers to samples of EBC does not affect the $\mathrm{pH}$ readings provided by the probe. These two tests help assure that the probe is not adversely functioning in the low ionic strength EBC.

\section{Normal EBC pH values}

Normal values of gas-standardized (" $\mathrm{CO}_{2}$-free") $\mathrm{EBC} \mathrm{pH}$ have been reported from multiple investigators and range between 7.5 and $8.1(3,8,9,12-21)$. In our normative database from 404 subjects, the mean $\mathrm{pH}$ was 7.83 , and the median $\mathrm{pH}$ was $8.0(12)$. The bell curve data distribution cuts off at approximately $\mathrm{pH}$ of 7.4, with a scattering of values below that level that are clearly not part of the normal distribution. EBC pH values below 7.4 occur in $6 \%$ of this population. These likely represent subjects with airway acidification that may be transiently symptomatic or asymptomatic, and may result from proximal acid reflux or from temporary innate immune responses against viral infections. From these data and data from over 6000 samples collected from over 600 subjects in other studies, our laboratory considers $\mathrm{pH}$ values less than 7.4 to be abnormal.

There are potential confounders of the $\mathrm{EBC} \mathrm{pH}$ levels. We have found that substantial intake of ethyl alcohol to the point of inebriation may modestly lower $\mathrm{EBC} \mathrm{pH}$. This may reflect alcohol's metabolism to acetic acid, which when exhaled can then alter EBC pH. It also may reflect alcohol-induced augmentation of gastroesophageal reflux to the laryngeal level. Additionally, oral ingestion of acidic beverages, and particularly fluids with volatile acids (vinegar) within 20 minutes of EBC collection may cause substantial artifact, with a lower $\mathrm{EBC} \mathrm{pH}$. Our protocol for providing $\mathrm{EBC}$ sample for $\mathrm{pH}$ assay includes that nothing except water should be ingested for 30 minutes prior to collection.

\section{Anatomic source of the determinants of EBC pH}

It is reasonable to assume that any significant acidification of the airway lining fluid that is exposed to the exhaled airstream will add acid to EBC. In patients who are endotracheally intubated, pharyngeal contribution will be nil. As part of the airway, the oropharynx likely can contribute to EBC pH when the sample is collected orally(22), but it does not in general 
have a strong effect. In keeping with this, salivary $\mathrm{pH}$ and $\mathrm{EBC} \mathrm{pH}$ do not correlate(3), and $\mathrm{pH}$ of EBC samples collected by oral breathing is the same as that collected subsequently from the endotracheal tube following intubation in patients undergoing elective surgery(3). That being noted, intentional profound experimental acidification of the pharynx can lead to temporary EBC acidification(13). This reflects the ability of EBC $\mathrm{pH}$ assays to identify the presence of a source fluid, at any airway level, sufficiently acidic to protonate certain bases to their volatile conjugate acids (acetic, formic acids).

Although the mouth can contribute to acidity of EBC, it also contributes to alkalinization of EBC by means of ammonia $\left(\mathrm{NH}_{3}\right)$ which is a volatile base produced in the mouth and lungs of many people in high concentrations and often is the highest concentration substance measurable in $\mathrm{EBC}(4)$. Initial speculation about $\mathrm{NH}_{3}$ controlling $\mathrm{EBC} \mathrm{pH}$ was forwarded (23), prompting studies to collect the empiric evidence has allowed for an improved understanding of $\mathrm{NH}_{3}$ 's role. Several interesting observations have been made in regard to oral ammonia. First, removal of potential oral ammonia contribution to EBC by bypassing the mouth by endotracheal intubation does not affect $\mathrm{EBC} \mathrm{pH}$. Second, removal of ammonia (likely along with other volatiles) from EBC by lyophilization and resuspension does not affect $\mathrm{EBC} \mathrm{pH}$. Third, it is uncommon to have a low $\mathrm{EBC} \mathrm{pH}$ value without a low $\mathrm{NH}_{3}$ level in $\mathrm{EBC}$, however it is common to find low $\mathrm{NH}_{3}$ levels with normal $\mathrm{EBC} \mathrm{pH}$ levels(4). These observations have lead to our current understanding that high oral production of $\mathrm{NH}_{3}$ can blunt the $\mathrm{EBC} \mathrm{pH}$ signal of volatile acids coming from the lungs, and thereby decrease the sensitivity of $\mathrm{EBC} \mathrm{pH}$ assays to identify lung acidification. However, when the acids exhaled from the airway are sufficient to overcome the modest neutralizing effect of oral $\mathrm{NH}_{3}$, a low $\mathrm{EBC} \mathrm{pH}$ signal represents low airway lining fluid $\mathrm{pH}$. An additional albeit less confident notion we have is that minor differences in $\mathrm{EBC} \mathrm{pH}$ values between groups within the $\mathrm{pH}$ range we consider normal is of uncertain meaning.

Extensive data have now been collected from intubated humans revealing that $\mathrm{EBC} \mathrm{pH}$ is low in disease states(10). Recently, it has been demonstrated in 12 patients that an endobronchially intubated healthy lung produces an EBC that is alkaline, whereas when the contralateral TB infected lung destined for excision is included in the EBC sampling, the values are acidic(24). These data provide invasive measurements necessary to help convince us that acidification of the lower airways indeed occurs and, as one would expect, indeed is heterogenous - with $\mathrm{pH}$ low in the sick portions of the lung.

\section{Research and clinical utility of EBC pH measurements}

$\mathrm{EBC} \mathrm{pH}$ is now perhaps the most commonly performed EBC assay. There are likely two reasons for this. Foremost is that investigators realize that airway $\mathrm{pH}$ deviation is a particularly relevant pathologic process that affects most every other aspect of lung disease that may interest them. One cannot ignore such a core component of how the airways and lungs function. Secondly is that the $\mathrm{pH}$ assay is relatively easy. Unlike most other assays in $\mathrm{EBC}$, there is no value of $\mathrm{pH}$ that is "undetectable". However, this is misleading. $\mathrm{pH}$ measurement represents a net proton concentration signal resulting from amounts and ratios of multiple acids and bases within the EBC. A "normal" EBC pH may mean that there are no volatile acids present (which can therefore be interpreted as "undetectable"). Or it may mean that volatile bases from an alkaline mouth or alkaline proximal airway have neutralized the volatile acids arising from an acidic area in the distal airway (thereby suggesting that $\mathrm{EBC} \mathrm{pH}$ has relevant limitations to its sensitivity, similar to other $\mathrm{EBC}$ assays). A low $\mathrm{EBC} \mathrm{pH}$ can confidently be said to result from a low airway lining fluid $\mathrm{pH}$ at some level. However a normal $\mathrm{EBC} \mathrm{pH}$ does not exclude that there is airway acidification present, unless there is little $\mathrm{NH}_{3}$ in the $\mathrm{EBC}$ as well. 
There are no doubt publications in the literature that have suffered from unrecognized deficiencies of $\mathrm{pH}$ probes, effects of freeze-sublimation that artifactually raises $\mathrm{EBC} \mathrm{pH}$, and excessively cold condenser temperatures. There are likely more technological validations that remain to be undertaken, but the field has advanced well, and application of this assay as an outcome measure in large clinical studies as well as to assist in clinical patient management are now reasonable considerations.

\section{Continuous EBC pH monitoring in intubated patients}

A system has been developed by Respiratory Research, Inc. (a University of Virginia faculty owned company of which the author of the current text is a director) and the United States Air Force that allows for measurement of EBC pH continuously. Known as the ALFA monitor, this system condenses breath from the expiratory port of mechanical ventilators, performs gas standardization at two levels using hospital wall oxygen supplies, and measures, displays and records the $\mathrm{EBC} \mathrm{pH}$ in digital and graphical formats. Because of the time delay for condensation and processing, the result is a second-to-second recording of an EBC $\mathrm{pH}$ moving average representing EBC production from the lungs during the previous 5 to 10 minutes. To date, we have performed continuous pH condensimetry on 40 humans and multiple pigs with various naturally or experimentally-induced lung diseases and find prominent acid production during disease worsening. With the oropharynx eliminated as a source of volatile acids, this system allows for selective measurement of lung acidity. In the absence of oral $\mathrm{NH}_{3}$ contribution, the $\mathrm{EBC} \mathrm{pH}$ becomes a higher sensitivity assay for airway acidity.

Diseases for which we have continuous $\mathrm{pH}$ condensimetry anecdotal data revealing lung acidification include acute asthma, cystic fibrosis, COPD, infection with respiratory syncitial virus, and ARDS. In these disease processes, $\mathrm{pH}$ changes gradually over hours to days. EBC $\mathrm{pH}>7.4$ is commonly associated with relative lung health, and $\mathrm{pH}$ levels with disease fall into the 4-6 range(10), similar to $\mathrm{pH}$ found in oral EBC collections from healthy and ill subjects respectively(8). In unpublished data, we have observed frequent gradual decline in $\mathrm{EBC} \mathrm{pH}$ during general anesthesia, which is as yet of uncertain significance. .Additionally, particularly when the endotracheal tube is not cuffed, we have observed rapid $\mathrm{pH}$ fluctuations that last for 10-15 minutes that are most likely attributable to gastric acid reflux and aspiration.

This technology is functioning for research to study time course of $\mathrm{pH}$ changes in the airways. At this time, knowing that the airway lining fluid $\mathrm{pH}$ is abnormally low may be only prognostically valuable for there is no clinically available therapeutic that is approved for use to neutralize acidic airway $\mathrm{pH}$. But airway $\mathrm{pH}$ modifying therapies are being tested, and when available will create a desire to know what the airway $\mathrm{pH}$ is in a given patient so that these airway $\mathrm{pH}$ modifying therapies appropriately can be used.

\section{Assessing for acid reflux-induced respiratory symptoms}

Initially, others and we considered that acid reflux could confound $\mathrm{EBC} \mathrm{pH}$ assays and prevent us from gaining the insights we wanted regarding airway $\mathrm{pH}$. However, with time, we have realized that the airways can acidify intrinsically or extrinsically, with the extrinsic pathways being inhalation of acid gases and aspiration of acid reflux. When considering things that confound, acid reflux is at the top of the list, for it confounds or complicates every respiratory illness. There is perhaps no more diagnostically frustrating entity in pulmonary medicine than acid reflux, because 1) the diagnostics are invasive and not designed or validated for use for respiratory system indications (e.g.- esophageal pH probes, which use normal reference ranges relevant to esophageal disease but irrelevant to aspiration disease); 2) acid reflux is so common. 
EBC $\mathrm{pH}$ offers a non-invasive assessment of airway $\mathrm{pH}$ that can be performed repeatedly. For example, transient acidification of the breath associated with chronic cough appears to be an excellent indicator that the patient's cough will respond to acid blockade therapy with proton pump inhibitors (PPI). In our studies, patients who responded to PPI by decreasing their cough symptoms invariably had transient breath acidification, and those whose cough failed to respond had no breath acidification (Figure 1). These findings provide for a novel method to determine which patients with asthma or COPD have confounding acid reflux without resorting to expensive and indefinite (and commonly indeterminate) PPI empiric trials.

\section{Studies of lung diseases in spontaneously breathing subjects}

The initial purpose for which we developed the $\mathrm{EBC} \mathrm{pH}$ assay was to open a window onto lung chemistry, with $\mathrm{pH}$ being certainly a centrally involved characteristic. The results of our work and those of others using the $\mathrm{EBC} \mathrm{pH}$ assay has provided the strongest support to date that the airways become acidified in numerous respiratory disorders. The $\mathrm{EBC} \mathrm{pH}$ assay, although not perfect, has undergone validation and vetting internationally. It is our current opinion that the settings in which $\mathrm{EBC} \mathrm{pH}$ decline is most relevant are in 1) acute asthma exacerbations; 2) COPD ; 3) Acute lung injury and ARDS (representing intrinsic airway acidification), and for 4) assessing gastric acid aspiration in the settings of chronic cough, asthma, COPD, lung transplant rejection, pulmonary fibrosis, vocal cord dysfunction and exercise induced dyspnea/bronchospasm. This purpose may be the most immediately valuable from a patient point of view, for there are therapies to help reflux induced symptoms if a diagnosis is made.

\section{Conclusion}

EBC is the only currently available convenient non-invasive ethically acceptable method of assessing airway acidity, especially when it comes to repeated sampling from acutely ill patients. Like all tests, EBC pH is neither perfectly sensitive nor specific for lower airway acidification. Many of the validation issues have been adequately addressed. It remains necessary to interpret the data cautiously, for acid at any level in the airway can lead to EBC acidification, and an absence of EBC acidification does not exclude the presence of some degree of airway acidification. EBC pH measures remain the most successful manner to date to evaluate the role of airway acidification in respiratory disease.

\section{References}

1. Ricciardolo FL, Gaston B, Hunt J. Acid stress in the pathology of asthma. J Allergy Clin Immunol 2004;113(4):610-9. [PubMed: 15100663]

2. Shin HW, Shelley DA, Henderson EM, Fitzpatrick A, Gaston B, George SC. Airway nitric oxide release is reduced following phosphate buffered saline inhalation in asthma. J Appl Physiol. 2006

3. Vaughan J, Ngamtrakulpanit L, Pajewski TN, Turner R, Nguyen TA, Smith A, Urban P, Hom S, Gaston B, Hunt J. Exhaled breath condensate $\mathrm{pH}$ is a robust and reproducible assay of airway acidity. Eur Respir J 2003;22(6):889-94. [PubMed: 14680074]

4. Wells K, Vaughan J, Pajewski TN, Hom S, Ngamtrakulpanit L, Smith A, Nguyen A, Turner R, Hunt J. Exhaled breath condensate $\mathrm{pH}$ assays are not influenced by oral ammonia. Thorax 2005;60(1): 27-31. [PubMed: 15618579]

5. Rothe MB, Siemers G, Decker R, M. The $\mathrm{pH}$-value of exhaled breath condensate - mainly influenced by exhaled volatile compounds 2005;26(49):2405.

6. Vaughan JW, Gaston B, MacDonald T, Erwin E, Malhotra N, Zaman K, Platts-Mills TAE, Hunt J. Acetic acid contributes to exhaled breath condensate acidity in asthma (abstr). Eur Respir J 2001;18(supp 33):P3083. 
7. Bunyan D, Smith A, Davidson W, Yu Y, Urban P, Naccara L, Platts-Mills J, Hunt J. Correlation of exhaled breath condensate $\mathrm{pH}$ with invasively measured airway $\mathrm{pH}$ in the cow. Eur Respir J 2005;26(49):2407.

8. Hunt JF, Fang K, Malik R, Snyder A, Malhotra N, Platts-Mills TA, Gaston B. Endogenous airway acidification. Implications for asthma pathophysiology. Am J Respir Crit Care Med 2000;161(3 Pt 1):694-9. [PubMed: 10712309]

9. Gessner C, Hammerschmidt S, Kuhn H, Seyfarth HJ, Sack U, Engelmann L, Schauer J, Wirtz H. Exhaled breath condensate acidification in acute lung injury. Respir Med 2003;97(11):1188-94. [PubMed: 14635972]

10. Walsh BK, Mackey DJ, Pajewski T, Yu Y, Gaston BM, Hunt JF. Exhaled-Breath Condensate pH Can Be Safely and Continuously Monitored in Mechanically Ventilated Patients. Respir Care 2006;51(10):1125-31. [PubMed: 17005057]

11. Kullmann T, Barta I, Lazar Z, Szili B, Barat E, Valyon M, Kollai M, Horvath I. Exhaled breath condensate pH standardised for CO2 partial pressure. Eur Respir J 2007;29(3):496-501. [PubMed: 17079255]

12. Paget-Brown AO, Ngamtrakulpanit L, Smith A, Bunyan D, Hom S, Nguyen A, Hunt JF. Normative data for $\mathrm{pH}$ of exhaled breath condensate. Chest 2006;129(2):426-30. [PubMed: 16478862]

13. Hunt J, Yu Y, Burns J, Gaston B, Ngamtrakulpanit L, Bunyan D, Walsh BK, Smith A, Hom S. Identification of acid reflux cough using serial assays of exhaled breath condensate $\mathrm{pH}$. Cough 2006;2:3. [PubMed: 16608520]

14. Borrill ZL, Smith JA, Naylor J, Woodcock AA, Singh D. The effect of gas standardisation on exhaled breath condensate pH. Eur Respir J 2006;28(1):251-2. 252-3. author reply. [PubMed: 16816353]

15. Brunetti L, Francavilla R, Tesse R, Strippoli A, Polimeno L, Loforese A, Miniello VL, Armenio L. Exhaled breath condensate $\mathrm{pH}$ measurement in children with asthma, allergic rhinitis and atopic dermatitis. Pediatr Allergy Immunol 2006;17(6):422-7. [PubMed: 16925687]

16. Carpagnano GE, Barnes PJ, Francis J, Wilson N, Bush A, Kharitonov SA. Breath condensate pH in children with cystic fibrosis and asthma: a new noninvasive marker of airway inflammation? Chest 2004;125(6):2005-10. [PubMed: 15189915]

17. Carraro S, Folesani G, Corradi M, Zanconato S, Gaston B, Baraldi E. Acid-base equilibrium in exhaled breath condensate of allergic asthmatic children. Allergy 2005;60(4):476-81. [PubMed: 15727579]

18. Kostikas K, Papatheodorou G, Ganas K, Psathakis K, Panagou P, Loukides S. pH in Expired Breath Condensate of Patients with Inflammatory Airway Diseases. Am J Respir Crit Care Med 2002;165(10):1364-70. [PubMed: 12016097]

19. Nicolaou NC, Lowe LA, Murray CS, Woodcock A, Simpson A, Custovic A. Exhaled breath condensate $\mathrm{pH}$ and childhood asthma: unselected birth cohort study. Am J Respir Crit Care Med 2006;174(3):254-9. [PubMed: 16675782]

20. Niimi A, Nguyen LT, Usmani O, Mann B, Chung KF. Reduced pH and chloride levels in exhaled breath condensate of patients with chronic cough. Thorax 2004;59(7):608-12. [PubMed: 15223872]

21. Rosias PP, Dompeling E, Dentener MA, Pennings HJ, Hendriks HJ, Van Iersel MP, Jobsis Q. Childhood asthma: Exhaled markers of airway inflammation, asthma control score, and lung function tests. Pediatr Pulmonol 2004;38(2):107-14. [PubMed: 15211692]

22. Horvath I, Hunt J, Barnes PJ. Exhaled breath condensate: methodological recommendations and unresolved questions. Eur Respir J 2005;26(3):523-48. [PubMed: 16135737]

23. Effros RM. Do low exhaled condensate NH4+ concentrations in asthma reflect reduced pulmonary production? Am J Respir Crit Care Med 2003;167(1):91, 91-2. author reply. [PubMed: 12502482]

24. Skrahina T, Smirnou A, Astrauko A, H H, Skrahin A. Separate lung exhaled breath condensate collection confirms intrapulmonary origin of exhaled breath condensate acidification (abstract). Eur Respir J 2007;30(suppl):365S. 

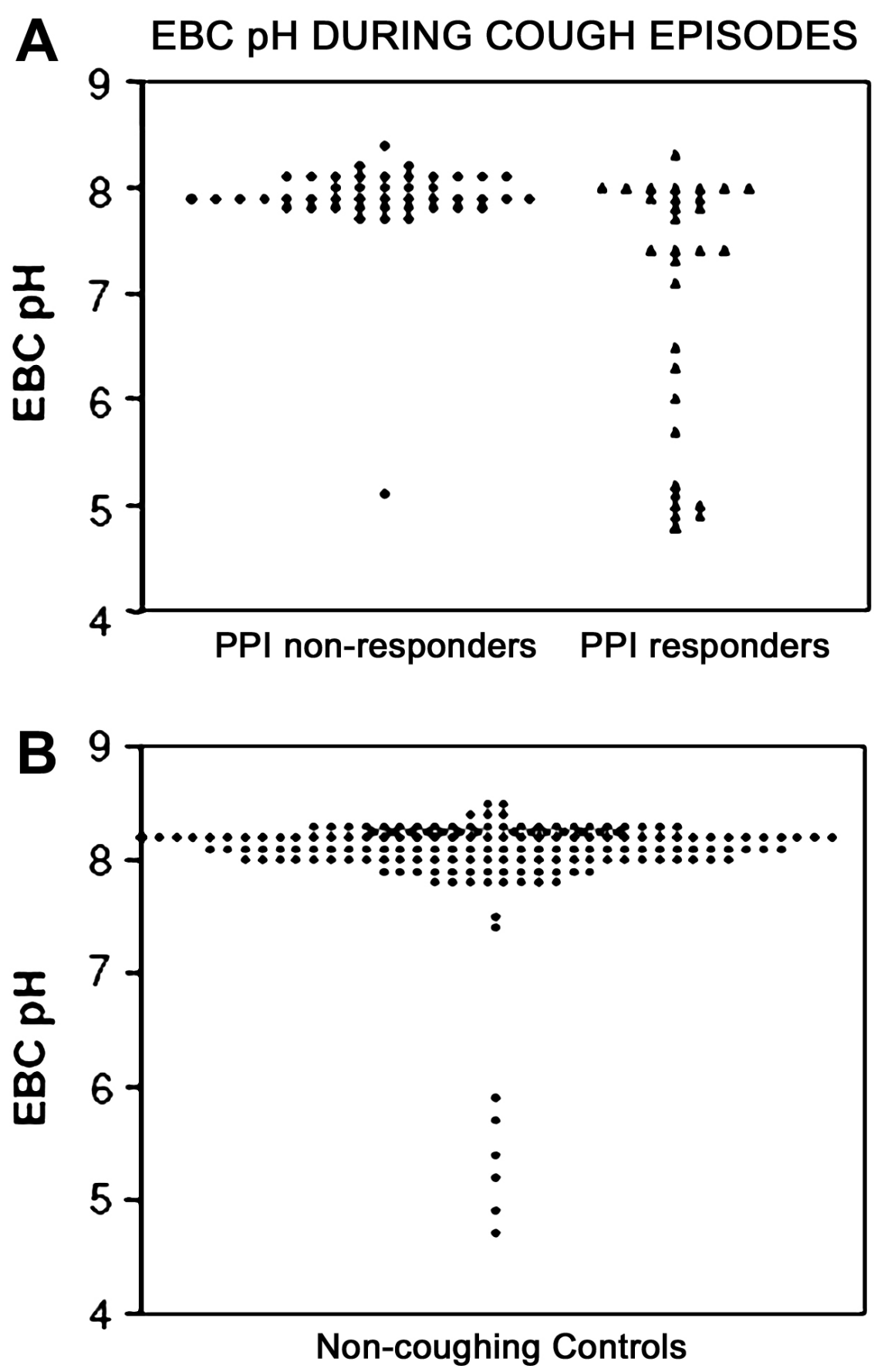

Figure 1.

$\mathrm{EBC} \mathrm{pH}$ values from patients who respond or do not respond to proton pump inhibition for their chronic cough (a) and non-coughing controls (b). Note that there are multiple samples collected from each patient, with all data plotted as individual samples. Approximately 50\% of the EBC samples from PPI-responsive coughers had low $\mathrm{pH}$ values. Note that all PPIresponsive patients had at least one episode of breath acidification during 4-8 breath collections collected at the time of cough. Adapted from reference ${ }^{13}$. 